Running head: Measuring the impact of child protection through Activation States

\author{
Revised paper submitted to Sport, Education and Society - 2004
}

\title{
Measuring the impact of child protection through Activation States
}

by

Celia H Brackenridge ${ }^{1}$, Zofia Pawlaczek ${ }^{2}$, Joy D. Bringer ${ }^{3}$, Claudi Cockburn ${ }^{4}$, Gareth Nutt ${ }^{5}$, Andy Pitchford ${ }^{5}$, Kate Russell ${ }^{5}$

1 independent researcher and Visiting Professor, University of Huddersfield, UK 2 Monash University, Australia

3 Sports Council for Wales

4 independent researcher, UK

5 University of Gloucestershire, UK

\section{Contact for correspondence:}

Celia Brackenridge

Celia Brackenridge Ltd,

Coalheughead Cottage

Harburn

By West Calder

West Lothian

EH55 8RT

celia.brackenridge@btopenworld.com

Tel: (UK+) 01506-873768

Fax: (UK+) 01506-871943

Note: This is an extended version of a paper first presented to the North American Society for the Sociology of Sport Annual conference, Montreal $29^{\text {th }}$ Oct $-1^{\text {st }}$ Nov 2003.

Acknowledgements: Thanks to the FA for permission to publish material from the project and to Adrian Ibbetson, Jacquelyn Allen Collinson, Chris Shelton and two anonymous reviewers for comments on an earlier draft. 
Measuring the impact of child protection ...

\title{
Measuring the impact of child protection through Activation States
}

\begin{abstract}
Child protection (CP) has risen to the top of the UK sports policy agenda in the past four years and the Football Association has invested in this major strategy as part of its commitment to "use the power of football to build a better future" (FA, 2000a). Evidencing the impact of child protection is, however, a complex task, exacerbated by the dearth of measurement tools that exist for this purpose in sport. This article presents a new model of 'Activation States' that has been designed and used to measure shifts in football culture as child protection has begun to impact upon the sport. The model is used to map changes over time related to the knowledge, feelings, actions and discourses of key stakeholders in football. The research for which the model was designed is a longitudinal study, commissioned by the English Football (soccer) Association, on the impact of the organisation's child protection strategy on the culture of soccer. Sample data from the project are used to illustrate the model and to examine its potential and limitations as a tool for measuring impacts in child protection and other social inclusion themes.
\end{abstract}

Key words: Child protection, measurement, culture, sport

Words: 6858 
Measuring the impact of child protection ...

Child protection (CP) has risen rapidly up the British sport policy agenda in recent years, largely in response to a number of high profile cases of child abuse in several major sports and, arguably, as part of a more general moral panic about child abuse in society (Brackenridge, 2001). For a variety of reasons, governing bodies of sport in England were initially slow to adopt child protection. Some denied that it was an issue in their sport, some were frightened of losing members through bad publicity and others felt that it was an affront to their integrity to suggest that child abuse might occur in the context of their particular sport. Following the lead of the Amateur Swimming Association (Myers \& Barrett, 2002), the Football Association (FA) in England invested significant resources in the development of a child protection strategy (The FA, 2000b). In order to monitor the effectiveness of this strategy and its impact on the game, the FA commissioned a longitudinal research project. This article briefly sets out the background to the project (which is more fully described in Brackenridge et al., 2004). The main purpose of the article, however, is to explore the conceptual difficulties of measuring the impact of an initiative such as CP on the culture of a sport organisation. Various models of cultural change are reviewed but rejected as inappropriate for this project. A new model of 'Activation States' is presented that was adopted by the FA researchers for presenting their findings through the life of the project. The model is presented with sample data from the project and its uses and limitations for measuring other social inclusion themes are discussed. 
Measuring the impact of child protection ...

\section{Child protection in sport}

Internationally, the pace of policy development in this field varies widely, from those nations who fail to acknowledge it as an issue at all to those who have put in place comprehensive systems to protect children and young people (for example Canada (www:caaws.ca), Australia (www:ausport.gov.au) and England (www:thecpsu.org.uk). Research on the subject is still relatively scarce but is gradually increasing as academics in both sport and children's studies recognise its importance (Harthill \& Prescott, 2004).

Policy development for child protection in English sport began in the past decade (Brackenridge \& Fasting, 2002) and was given a major boost by the establishment of the Child Protection in Sport Unit (CPSU) in January 2001 (Boocock, 2002). The Unit is co-funded by the National Society for the Prevention of Cruelty to Children (NSPCC), the country's largest children's charity, and Sport England. It acts as a one-stop shop for advice and referrals about child abuse and protection sport. Prior to the establishment of the CPSU, various piecemeal CP initiatives were promoted by individual sport organisations, most notably the Amateur Swimming Association (Myers \& Barrett, 2002), coaching groups such as the sportscoachUK (formerly the National Coaching Foundation) (Malkin et al., 2000) and child welfare organisations such as the NSPCC (Brackenridge, 2001). The CPSU Unit has published national policy standards for CP (CPSU, 2003) and all sports in receipt of state grants have to demonstrate compliance by implementing CP action plans as a criterion of funding. 
Measuring the impact of child protection ...

\section{The Child Protection in Football Research Project}

During the 1990s, the FA, along with many other governing bodies of sport, became increasingly aware of child protection as an issue both in society in general and sport in particular. High profile publicity from cases in other sports, together with the experience of managing the Football Association National School for talented boy players, and occasional cases of abuse within football, led the FA to seek advice about child protection from the NSPCC. ${ }^{1}$ What followed was the development and launch of a comprehensive CP strategy for football (brand named Goal), across a range of operational areas such as education and training, communication and case management (FA, 2000b).

By 2000, many other governing bodies in the UK had set up policies and procedures for CP but, at that time, few had successfully implemented these or collected evidence of their impact or effectiveness (Brackenridge, 2001; Harthill \& Prescott, in press). Also, whilst there were examples of evaluation and monitoring work on anti-racism in some sport organisations (such as cricket) the FA is believed to be the first in the world to have commissioned such research on child protection. $^{2}$

The project comprised two major stages:

Phase 1 (Audit): An independent audit of current CP provision throughout English football, from the Premier League down to local leagues (excluding non-FA affiliates) during 2002.

Phase 2 (Review): A longitudinal study to monitor and review the impact of the FA's CP strategy as it rolled out from 2003-2006. 
Measuring the impact of child protection ...

In line with the FA's own strategic directives for research, both quantitative and qualitative monitoring was required in both phases of the research. The main purpose of the Phase 1 (2002) was to provide evidence about the need for the FA to change or maintain its policy plans for child protection in the year 2003. The research design included quantitative methods (internet surveys and analysis of abuse referral case files ${ }^{3}$ ) and qualitative methods (case studies of 33 football clubs throughout England and over 200 interviews with key stakeholders, defined as those being affiliated, close to children and with the potential to be change agents). Full details of the sample are available in Brackenridge et al., (2004).

Most social research suffers from the criticism that it offers only a temporal 'snapshot' of a situation, one that may well give an unfair distortion of the picture at an unrepresentative moment. Longitudinal research, on the other hand, provides an opportunity to measure change over a period of time, in this case the five years from 2002-2006, to describe trends and to identify the direction and intensity of any change. It often starts with classic 'gap analysis' whereby a vision of change is set against the current state of affairs (see Figure 1).

[Insert Figure 1 about here - gap analysis]

\section{The problem of cultural change}

Since the late 1970s, organisations in receipt of public finances have undergone management reforms. These reforms have frequently been seen as solutions for overcoming the shortcomings attached to the bureaucratic model. The management of change has been a major topic of interest to both 
Measuring the impact of child protection ...

researchers and managers. In education, for example, the work of Fullan (1982, and with Stiegelbauer, 1991) has underpinned much subsequent research on innovation and change in schooling. Within physical education and sport specifically, change has been investigated within curriculum (Cothran, 2001; Johns et al., 2001), pedagogy (Pope \& Sullivan, 1998; Curtner-Smith, 1999) and the role of the physical education teacher (Flintoff, 2003). Changes in structures (such as the authority systems within an organisation) sometimes precede and sometimes follow changes in the culture, ethos or feel of an organisation. In sport, change management, and the management of cultural change especially, have been problematised and investigated by, for example, Slack and Hinings (1992) and Colyer (2000).

For change to occur successfully, it has also come to be understood that, within the architecture of an organisation's structure, changes in leadership are necessary (Weese, 1996). The appointment of a new Chief Executive of the FA in February 2000 brought about a shift in organisational direction which involved major reforms. In any organisation the CEO is a major change agent and, in this instance, the new FA CEO's managerial authority was central to the vision for the CP Strategy. In contrast with former practices in the FA, he introduced a Strategic Plan that explicitly called for strong values in the game, including quantitative and qualitative research evidence to underpin policy development (FA, 2000a), and a commitment to ethical policies and practices. The researchers worked on the premise that the $\mathrm{CP}$ initiative was one tool of cultural change in this process. 
Measuring the impact of child protection ...

At the outset, the challenge for the FA was how to move the football community from reactive to proactive engagement with the change agenda. The challenge for the research team, therefore, was how to measure this in respect of CP. Like many other governing bodies of sport, the FA's development of CP was a recent addition to working practices. The researchers therefore had to identify those stakeholder groups who were either restraining (including doing nothing) or facilitating change, both at the outset and after the implementation of the Goal CP campaign. It was for this reason that the model, described below, was developed and a wide range of stakeholder groups was consulted at every level of the game, from the professional Premier League down to local junior clubs.

Organisational ritual is one area that can be reviewed to detect the way in which a programme or policy impacts upon culture. For example, rituals are common in the FA as in any organisation, and the consolidation of CP would be overtly expressed through the rewarding of 'champions' of the Goal campaign. This is sometimes referred to as rites of integration (Subramaniam \& Ashkanasy, 2001) and includes events such as the staging of conferences or meetings that praise the groups and individuals who are facilitating change. In the case of the $\mathrm{FA}$, an annual CP conference was established that disseminated information on 'good practice' (The FA, 2002 and 2003), a newsletter was produced which reported, for example, the numbers of people attending the FA's own child protection and good practice workshop in each county, and an ambassadors scheme was established to promote the CP programme using top football stars such as Alan Shearer (a former England captain) and Sir Bobby Robson (a 
Measuring the impact of child protection ...

former England coach). All these developments indicated that change of some sort was occurring. The most potent indicator of change, however, is the behaviour of change agents. The researchers therefore undertook repeat interviews with key stakeholders in order to map the impact of the CP programme on those who were in a position to both effect and symbolize change at the FA.

It is well known that participants in social experiments change their actions to suit those expected by their observers. For example, in industrial studies of piecework rates, outputs increased among the experimental group. This is known as the Hawthorn effect after one particular study of industrial behavior (Roesthlisberger \& Dickson, 1939). It comes about because people know that they are a part of a study, feel special as a consequence and change their behaviour either consciously or unconsciously to 'please' the researchers. In this project, the sample groups in the qualitative case studies and interviews were expected to want to 'look good' in front of the researchers and therefore to pose as positive facilitators of change towards $\mathrm{CP}$. This was certainly one of the unintended outcomes of the FA CP project in its early stages, as gatekeepers for the case studies, and indeed some of the case study personnel, attempted to show off about their CP work and credentials to visiting researchers.

\section{Critique of theories of change}

Change is the subject of intensive theorization and writing in academe. Rollnick et al. (2000) describe change as something that someone else thinks would be good for you: in reality this is often an employer or government 
Measuring the impact of child protection ...

attempting to realise strategic goals. In relation to $\mathrm{CP}$ in football, this is a relatively new concept but one which has had significant media and public attention in recent years, so there was reason to think that the community of football would be ready to adopt it. However, there were also reasons why people in sport were slower than other groups to embrace the need for change in $\mathrm{CP}$ practices, for example fear of litigation (Brackenridge, 2001), so it was unclear exactly what the attitudes of people in the game might be. In addition, sport organisations have, in the past decade or so, undergone many changes in management practices from their 'kitchen table' origins to executive office style of management. More commonly such changes have been presented as part of the process of professionalisation or modernisation (UK Sport, 2002): it is the practices associated with this process that may impact on the 'ownership' of strategic goals at the FA. For example, for strategy to be realised it requires 'internalisation', yet for many grassroots volunteers in the game of football, strategy developments such as the Goal campaign were either unheard of or regarded as a product of remote analysis.

\section{[Insert Figure 2 about here - sources of theoretical ideas]}

\section{Individuals and change}

The process of change can be applied to both individuals and organisations. The sources of literature and theories of change include health psychology, management studies, education studies and organisational sociology, among others (see Figure 2). Rollnick et al. (2000) report that there is an array of possible psychological models and theories that could be adopted in 
Measuring the impact of child protection ...

trying to explain individual/stakeholder changes. Some of the most prominent that might be applied to CP in football include:

Health Belief Model (Becker, 1974)

Theory of Reasoned Action (Ajzen \& Fishbein, 1980)

Theory of Planned Behaviour (Ajzen, 1988)

Health Action Process Approach (or HAPA) (Schwarzer, 1992)

Each of these is based on tracking individual, personal change rather than organisational change per se and each draws on psychological constructs. Typically, stage models set out a sequential list of phases through which the individual passes on their way to sustainable behaviour change. Some of the major stage models are summarized in Table 1.

\section{[Insert Table 1 about here - models of change]}

Criticisms of using stage models for measuring change are leveled by Davidson (1998) who suggests, for example, that the Transtheoretical Model (TTM), proposed by Prochaska and DiClemente (and widely adopted in health campaigns) is atheoretical rather than transtheoretical and based on a continuum rather than discrete stages. Davidson argues that the divisions in TTM are not psychometrically sound and therefore that questions derived from the various stages are flawed. Summarising, Rollnick et al. (2000, p. 192) say

...there is no single model that adequately explains the sometimes baffling complexity of behaviour change... Neither is there one theory which is close to being uniformly endorsed by researchers and theorists. 
Measuring the impact of child protection ...

Individuals will only change their actions towards an issue if they accept that it is important and if they have the confidence to do so. As people move from 'not ready' to 'unsure' to 'ready', so they give voice to different anxieties, options and feelings. Measuring the willingness of different stakeholders to engage the change process in football, in this case to adopt CP policies and practices, is an important first step in describing how to avoid resistance. One of the difficulties with change models is that they appear to depend on a linear pathway. Even if the 'stages' are psychometrically valid, it is very difficult to operationalise them without begin deterministic (i.e. $X$ determines or causes $Y$ which then determines

Z). A second major criticism of change models is that they do not adequately account for conflict and regression where, for example, someone moves back to an earlier stage, challenges or opts out of a given stage. The question therefore arises whether cultural change can be reduced to a series of sequential stages? It is because of these reservations about existing change models that the researchers adopted a completely new framework for this research project.

\section{Organisations and group change}

The question of organisational, as opposed to individual, change is even more complex since it involves multiple, and often competing, internal and external environmental forces, for example economic factors, industrial relations and organisational history. In the first year of this research project the impact of $\mathrm{CP}$ was assessed only among stakeholder groups within football, on the assumption that, collectively, they contributed much of the potential momentum 
Measuring the impact of child protection ...

for change in the game. It is clear, however, that in the later stages of the project the forces at work in the external environment should also be weighed in the change equation.

A further limitation is that there is no real baseline data in this project as the FA's CP work began in practice long before the official launch of the Goal campaign and no data were available about earlier awareness or action levels. Also, despite the exhortations of the FA's Strategic Plan there was no tightly specified vision of what football should be like that could be used as a yardstick for measuring progress. People fluctuate and regress in their attitudes to CP and to other ethics and welfare themes, such as gender equity or social inclusion: change is not always in a positive direction so the researchers must capture the dynamic status of engagement with $\mathrm{CP}$ and not assume that progress will be linear, positive, causally linked to the FA CP Strategy or, indeed, readily measured.

It is easy to assume that those charged with carrying out an agenda for change through, for example, CP are knowledgeable. Indeed, one of the dangers of the CP 'expert' is that they give advice and information (down) to the (assumed) unaware football person, be they a parent, a referee or a coach. In reality, however, it is wise never to assume that receivers of CP messages are necessarily rational or well-informed (especially given the emotive nature of the subject) or, on the other hand, completely ignorant since many people in the game have CP awareness and experience through their professional or daily 
Measuring the impact of child protection ...

lives. Similarly, lack of change or poor uptake of the CP message could be attributable to poor delivery, competing priorities, something else or all of these.

Because of the limitations of existing models of behaviour change (for individuals), and the need to find an approach that would both reflect the social, organisational and policy impacts of $\mathrm{CP}$ and be readily intelligible to the football community, the researchers developed the new change framework. The intention was to take into account both those forces that could block or facilitate change and the fact that the change agenda and CP programme had been launched prior to the start of the research project.

\section{A Model of Activation States}

The term 'Activation States' was adopted to indicate the level of activation of each stakeholder group towards CP in football. Five states were identified:

- Inactive i.e. demonstrating no knowledge or commitment to CP

- Reactive i.e. demonstrating reluctant commitment and engagement

- Active i.e. demonstrating satisfactory awareness and involvement

- Proactive i.e. demonstrating full commitment and advocacy

- Opposed i.e. either overtly critical of, or covertly against, the CP initiative

\section{[Insert Table 2 about here - Activation States]}

Each of these was then set against the voices, knowledge, feelings and actions and of the stakeholders being interviewed (Table 2).

- Voices/discourses (What people say about CP in football) 
Measuring the impact of child protection ...

- Knowledge and experience (What people know through experience - their awareness, interest or understanding)

- Feelings (What people feel - their attitudes and emotions)

- Action (What people do/have done - their achievements and behaviour)

The adoption of Activation States allowed the researchers to give a simple visual representation of the profile of each stakeholder response and to differentiate where these responses were not internally consistent. For example, some people express enthusiasm and commitment to $\mathrm{CP}$ at an emotional level (proactive feelings) but report having done very little about it (inactive action). Others might talk sceptically or express diffidence (overtly opposed voices) yet be comparatively well informed about the issue (active knowledge).

\section{[Insert Figure $3 a$ and $b$ here - sample profiles]}

The sample profiles (see Figures $3 a$ and $b$ ) are used here to present some of the results from the project thus far (Brackenridge et al., 2002, 2003, 2004) and to depict the activation states profiles for each stakeholder group. In the samples, the respondents' most commonly observed (modal) Activation States from the interview data are presented. The first year data represent the audit or baseline. The second year data reflect the impact of the CP programme. Examples from the analysis of the transcripts are shown in Tables $3 a$ and $3 b$.

[Insert Tables $3 a$ and $3 b$ here - Samples from interviews]

Researchers were trained in using the analysis system at a special staff development day where the system was debated and refined. Working in pairs, 
Measuring the impact of child protection ...

all researchers read the same sample of transcripts and then allocated them to the sections of the Activation States grid. Inter-rater reliability ranged from $60-80$ per cent which is deemed by Weiss (1998) to be above the acceptable threshold for qualitative analysis. Findings from a series of internet-based stakeholder surveys were set against the profiles to augment the discussion in the annual reports: these are reported elsewhere (Brackenridge et al., 2002, 2003, 2004).

\section{Uses and limitations of the model}

The Activation States model has several potential uses:

- plotting where different stakeholders are now;

- charting changes over the five years;

- identifying dissonances within and between groups of stakeholders;

- checking whether quantitative and qualitative data agree;

- displaying change in a user-friendly way;

- offering a model for tracking the impact of other welfare issues, for example gender or race equity.

Whilst the model may look linear it is not meant to be deterministic nor to imply any psychometric properties. It is intended to be used as a heuristic device rather than a calibrated 'scale' and thus to give a sense of how a new policy initiative has impacted on different stakeholder groups and where further action might be required by the organisation in order to develop commitment and cooperation. The 'opposed' elements of the model are of particular interest, therefore, because they help to diagnose dissonance and dissent, whether overt 
Measuring the impact of child protection ...

or covert. Also, whereas there are strong echoes of psychological constructs of 'attitude' and 'motivation' in the model, there is an attempt here to capture the social and interpersonal processes that accompany policy change. The inclusion of the voices/discourse components of the model is a clear departure from the psychological paradigm and one which attempts to account for the power of voice in cultural resistance (Clandinin \& Connelly, 1998; Sparkes, 2002).

One test of the model of Activation States will be the effectiveness with which it is used to explain the findings from the FA's longitudinal research on child protection. Another will be its applicability to other social, ethical and management themes and issues. To meet these tests, the model will have to be capable of charting fluctuations in the impact of both the micro and the macro climates and the internal and external business environments. Potential business applications include, for example, staff engagement with restructuring and mergers, rebranding or relocation. Applications in service organisations could include: responses to privatisation or trust status in schools or hospitals, changes in health and safety practices or campaigns for greater social or ethnic diversity. In any field where the imperative for an evidence-base is driving policy implementation the Activation States model should be able to provide a picture of change.

\section{Conclusions}

This article has set out a framework for measuring the impact of child protection on the stakeholders, and thus the culture, of football. The model has been devised in an attempt to capture the complexity of different stakeholders' 
Measuring the impact of child protection ...

engagement with ethics and welfare issues in sport and, at the same time, to provide a visual means of demonstrating change to those responsible for implementing these policy agendas. Whilst the model of Activation States has been developed from research into child protection in sport it has potential applicability well beyond this field. Its utility as a heuristic device appears to offer benefits for anyone with a social change agenda who is seeking to implement evidenced-based policy.

One of the major dangers of any CP campaign like Goal is the possibility of stakeholders suffering from what might be termed 'welfare overload'. In other words, if people involved in football sense that they are being judged too harshly, or pushed to far too soon, then there may either be a backlash against $\mathrm{CP}$ (Finkelhor, 1994) or boredom may set in as Goal, like any other product or service, reaches the end of its life cycle. It remains to be seen whether this happens with Goal and whether, in particular, the launch of further welfarerelated FA initiatives (for race, disability and gender equity) might be perceived by some as a step too far. Despite the strong advocacy initially from the FA's CEO, his departure from the FA in late 2002 impacted on the research project, leading to a reduction in the scale of the study in year two. It remains to be seen what influence new leadership arrangements may have on the research project in particular and on the ethics and equity initiatives of the Football Association more generally. 
Measuring the impact of child protection ...

\section{Notes}

1. The most notorious case in the UK was that of former Olympic swimming coach, Paul Hickson, who was jailed in 1995 for raping and sexually assaulting female swimmers in his care over a twenty year period. In football, several cases involving scouts, junior coaches or other soccer personnel have hit the media headlines including that of Graham Rix, former coach at Chelsea Football Club (Millward, 1999), who was jailed for 12 months after admitting having unlawful sex with a girl of 15 , the conviction of youth coaches at Crewe Alexandra, Celtic and Crystal Palace football clubs (Pittaway, 2000) and false allegations of sexual misdemeanours again former Southampton FC manager Dave Jones (Chrisafis, 2000).

2. A team of ten researchers was selected with a mix of backgrounds including: sports development, coaching and sports administration, some but not all of which was related to football. All had higher degrees in sport or the social sciences. The group comprised lecturers, full-time contract researchers in universities and independent researchers, three of whom were men and the rest women. All researchers had been trained in child protection in sport or were themselves tutors of the Sports coach UK workshop on child protection in sport. Preliminary training in research methods for the project was delivered prior to the data collection phase. In addition, a research guidelines handbook was prepared for the project each year that set out the research design, methods, questions, management arrangements, interview schedules, and ethics, confidentiality and media protocols for the project together with required reading. Periodic review 
Measuring the impact of child protection ...

and training days were held and information bulletins issued to update the researchers as the project developed.

3. Access to these confidential files was negotiated within the terms of the ethics protocols agreed for the project and approved by the Research Ethics Committee of the University of Gloucestershire.

\section{References}

AJZEN, I. (1988) Attitudes, personality and behavior (Chicago, IL, Dorsey Press).

AJZEN, I. \& FISHBEIN, M. (1980) Understanding attitudes and predicting social behavior (Engelwood Cliffs, NJ: Prentice Hall).

BECKER, M.H. (1974) The health belief model and personal behavior, Health Education Monographs, 2, pp. 326-373.

BOOCOCK, S. (2002) The Child Protection in Sport Unit, Journal of Sexual Aggression, 8 (2), pp. 99-106.

BRACKENRIDGE, C.H. (2001) Spoilsports: Understanding and preventing sexual exploitation in sport. (London, UK: Routledge).

BRACKENRIDGE, C.H., BRINGER, J.D., COCKBURN, C., NUTT, G., PAWLECZEK, Z., PITCHFORD, A. \& RUSSELL, K. (2004) The Football Association's Child Protection in Football Research Project 2002-2006:

Rationale, design and first year results, Managing Leisure - An International Journal, 9, pp. 30-46.

BRACKENRIDGE, C.H., BRINGER, J.D., COCKBURN, C., NUTT, G., PAWLACZEK, Z., PITCHFORD, A. \& RUSSELL, K. (2002) The Child Protection in Football Research Project 2002. Final Report on Year One - Audit. Unpublished report, (London: The Football Association).

BRACKENRIDGE, C.H., COLLINSON, J.A., COCKBURN, C., IBBETSON, A., NUTT, G., PAWLACZEK, Z., PITCHFORD, A. \& RUSSELL, K. (2003) The Child Protection in Football Research Project 2003. Final Report on Year Two Review. Unpublished report (London: The Football Association). 
Measuring the impact of child protection ...

BRACKENRIDGE, C.H., \& FASTING., K. (2002) Sexual harassment and abuse in the sport - the research context, Journal of Sexual Aggression, 8 (2), pp. 315.

CHILD PROTECTION IN SPORT UNIT (2003) National Policy Standards for Child Protection in Sport (London, UK: CPSU/Sport England).

CHRISAFIS, A. (2000) Former football manager cleared of child abuse charges, The Guardian $6{ }^{\text {th }}$ December, p. 2.

CLANDININ, D.J. \& CONNELLY, M. (1998) Personal experience methods, in: N.K. DENZIN \& Y.S. LINCOLN (Eds) Collecting and Interpreting Qualitative Materials. (London: Sage).

COLVER, S. (2000) Organizational culture in selected Western Australian sport organizations, Journal of Sport Management, 14(4), pp. 321-341.

COTHRAN, D.J. (2001) Curricular change in physical education: success stories from the front line, Sport, Education and Society, 6(1), pp. 67-79.

CURTNER-SMITH, M.D. (1999) The more things change the more they stay the same: factors influencing teachers' interpretations and delivery of national curriculum physical education, Sport, Education and Society, 4(1), pp.75-97.

DAVIDSON, R. (1998) The transtheoretical model: A critical overview, in: R.W. MILLER \& N. HEATHER (Eds) Treating Addictive Behaviours 2nd Ed. (New York: Plenum).

FINKELHOR, D. (1994) The "backlash" and the future of child protection advocacy, in: J.E.B. MYERS (Ed) The Backlash: Child Protection Under Fire. (London: Sage).

FLINTOFF, A. (2003) The school sport co-ordinator programme: changing the role of the [physical education teacher, Sport, Education and Society, 8(2), pp. 231-250.

FOOTBALL ASSOCIATION (2000a) 3 Year Strategic Plan (Unpublished document, March $24^{\text {th }}$ ).

FOOTBALL ASSOCIATION (2000b) Strategic Plan for Child Protection (Unpublished document, November).

FOOTBALL ASSOCIATION (2002) CD Rom of the Annual Child Protection in Football Conference 'Making a Change, Making a Difference' (Derby, UK: The Media Group tv). 
Measuring the impact of child protection ...

FOOTBALL ASSOCIATION (2003) CD Rom of the Annual Child Protection in Football Conference 'Putting Children First. GOAL - A better future for football'. (Derby, UK: The Media Group tv).

FULLAN, M.G. (1982) The Meaning of Educational Change (Toronto, CAN: OISE Press)

FULLAN, M.G. with STIEGELBAUER, S. (1991) The New Meaning of Educational Change (New York: Cassell).

HARTHILL, M. \& PRESTCOTT, P. (in press) Sport and child protection: The impact of implementing a child protection policy in Amateur Rugby League, Leisure Studies, ... pp. tbc.

HAYES, J. (2002) The Theory and Practice of Change Management (Basingstoke, UK: Palgrave).

JOHNS, D.P., Ha, A.S.C. \& Marfarlane, D.J. (2001) Raising activity levels: a multidimensional analysis of curriculum change, Sport, Education and Society, 6(2), pp. 199-210.

MALKIN, K., JOHNSTON, L. \& BRACKENRIDGE, C.H. (2000) A critical evaluation of training needs for child protection in UK sport, Managing Leisure - An International Journal, 5, pp. 151-160.

MILLWARD, D. (1999) Chelsea football coach jailed for year after sex with girl, 15 , The Daily Telegraph, $27^{\text {th }}$ March.

MYERS, J. \& BARRETT, B. (2002) In at the Deep End: A new insight for all sports from analysis of child abuse within swimming (London, UK: NSPCC).

PITTAWAY, B. (2000) FA on the attack as paedophiles target football's talent factories, The Observer, $9^{\text {th }}$ January.

POPE, C.C. \& O'SULLIVAN, M. (1998) Culture, pedagogy and teacher change in an urban high school: how would you like your eggs done? Sport, Education and Society, 3 (2), pp. 201-226.

PROCHASCA, J.O. \& DICLEMENTE, C.C. (1986) Towards a comprehensive model of change, In: R.W. MILLER \& N. HEATHER (Eds) Treating Addictive Behaviors (2nd ed.) (New York: Plenum).

ROETHLISBERGER, F.J. \& DICKSON, W.J. (1939) Management and the Worker (Boston, MA: Harvard University Press). 
Measuring the impact of child protection ...

ROLLNICK, S., MASON, P. \& BUTLER, C. (2000) Health Behavior Change: A guide for practitioners (London: Livingstone Churchill).

SCHWARZER, R. (Ed) (1992) Self Efficacy: Thought control of action (Washington, DC: Hemisphere).

SLACK, T. \& HININGS, B. (1992) Understanding change in national sport organizations: an integration of theoretical perspectives, Journal of Sport Management 6(2), pp. 114-132

SPARKES, A.C. (2002) Telling Tales in Sport and Physical Activity: A qualitative journey (Leeds: Human Kinetics).

SUBRAMANIAN, N. \& ASHKANASY, N.M. (2001) The effect of organisational culture perceptions on the relationship between budgetary participation and managerial job-related outcomes, Australian Journal of Management, 26 (1), pp. 35-55.

UK SPORT (2002) Modernisation Programme http://www:uksport.gov.uk

WEESE, W.J. (1996) Do leadership and organizational culture really matter? Journal of Sport Management, 10(2), pp. 197-206

WEISS, C.H. (1989) Evaluation $2^{\text {nd }}$ Ed. (Saddle River, NJ: Prentice Hall.) 
Measuring the impact of child protection ...

\section{LIST OF CAPTIONS}

Figure 1 Model of cultural change showing gap analysis

Figure 2 Cultural change - sources of theoretical ideas

Figure 3a Sample Activation States stakeholder profile: Coaches, managers and teachers in 2002 and 2003

Figure 3b Sample Activation States stakeholder profile: Parents/carers and guardians in 2002 and 2003

Table 1 Overview of stages of change models

Table 2 'Activation states' with regard to child protection in football (c) CB Ltd.2002

Table 3a Samples from coaches, managers and teachers' interviews

Table 3b Samples from parents/carers and guardians' interviews 
Measuring the impact of child protection ...

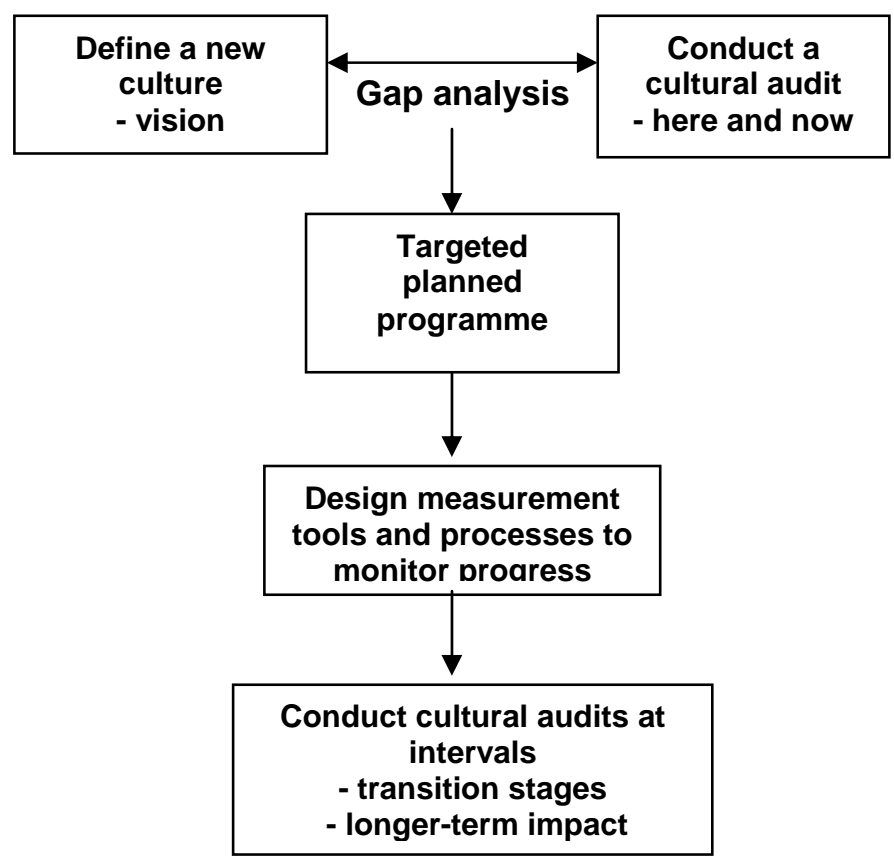

Figure 1 Model of cultural change showing gap analysis 


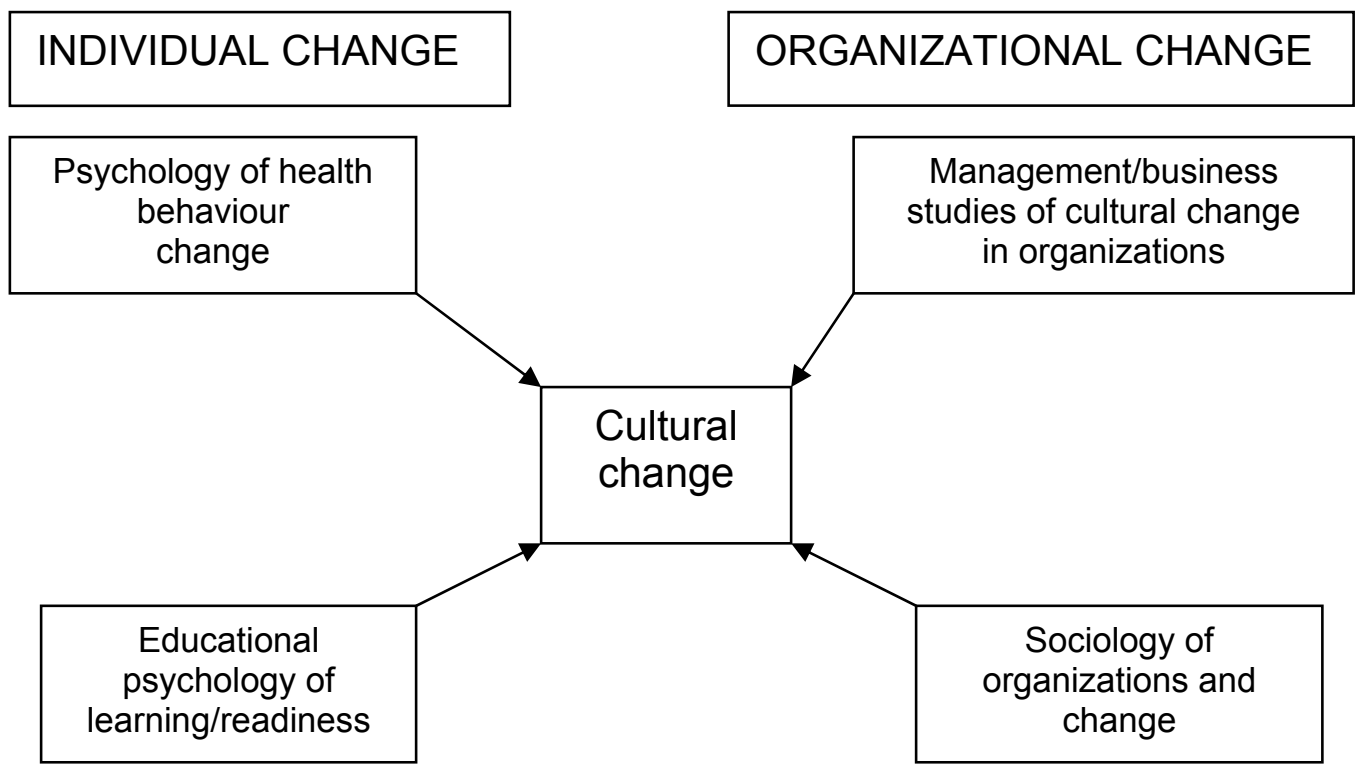

Figure 2 Cultural change - sources of theoretical ideas 


\begin{tabular}{|c|c|c|c|c|c|}
\hline & Inactive & Reactive & Active & Proactive & Opposed \\
\hline Voices & & 0 & $\Delta$ & & \\
\hline Knowledge & & $\Delta$ & C & & \\
\hline Feelings & & & $\Delta$ & & \\
\hline Action & & $\Delta$ & C & & \\
\hline
\end{tabular}

Key: $\boldsymbol{\Delta}$ = Mode for $2002(n=28) ; 0$ = Mode for $2003(n=25)$

Figure 3a Sample Activation States stakeholder profile: Coaches, managers and teachers in 2002 and 2003

\begin{tabular}{|l|c|c|c|c|c|}
\hline & Inactive & Reactive & Active & Proactive & Opposed \\
\hline Voices & $\mathbf{\Delta}$ & & $\mathbf{0}$ & & \\
\hline Knowledge & $\mathbf{\Delta}$ & $\mathbf{0}$ & & & \\
\hline Feelings & $\mathbf{\Delta}$ & & $\mathbf{0}$ & & \\
\hline Action & $\mathbf{\Delta}$ & $\mathbf{0}$ & & & \\
\hline
\end{tabular}

Key: $\mathbf{\Delta}$ = Mode for $2002(n=25) ; 0$ = Mode for $2003(n=28)$

Figure 3b Sample Activation States stakeholder profile: Parents/carers and guardians in 2002 and 2003 
Measuring the impact of child protection ...

\section{Table 1 Overview of stages of change models}

\begin{tabular}{|c|c|c|c|c|c|c|c|}
\hline AUTHOR(S) & STAGES & & & & & & \\
\hline $\begin{array}{l}\text { Prochaska } \\
\text { \& Di } \\
\text { Clemente } \\
(1986)\end{array}$ & $\begin{array}{l}\text { Pre-contem } \\
\text { plation }\end{array}$ & $\begin{array}{l}\text { Contem- } \\
\text { plation }\end{array}$ & Preparat'n & Action & \multicolumn{3}{|c|}{ Maintenance } \\
\hline $\begin{array}{l}\text { Hayes } \\
(2002)\end{array}$ & & Awareness & Initiation & Implement'n & Evaluation & \multicolumn{2}{|c|}{ Institutional'isn } \\
\hline $\begin{array}{l}\text { Rollnick } \\
\text { et al. } \\
(2000) \\
\end{array}$ & & & & $\begin{array}{l}\text { Congruence } \\
\text { (Compliance) }\end{array}$ & \multicolumn{3}{|l|}{ Adherence } \\
\hline $\begin{array}{l}\text { Fullan } \\
\text { (1991) }\end{array}$ & & & $\begin{array}{l}\text { Phase I } \\
\text { Initiation } \\
\text { Mobilisat'n } \\
\text { Adoption }\end{array}$ & $\begin{array}{l}\text { Phase II } \\
\text { Implement'n } \\
\text { Initial use }\end{array}$ & $\begin{array}{l}\text { Phase III } \\
\text { Continuatio } \\
\text { Incorporatio } \\
\text { Routinsatio } \\
\text { Institutional }\end{array}$ & & Outcome \\
\hline
\end{tabular}




\section{Table 2 'Activation states' with regard to child protection in football $\quad$ C CB Ltd.2002}

\begin{tabular}{|c|c|c|c|c|c|}
\hline State -> & INACTIVE & REACTIVE & ACTIVE & PROACTIVE & OPPOSED \\
\hline $\begin{array}{l}\text { Voicesl } \\
\text { discourses } \\
\text { [What people } \\
\text { say about CP in } \\
\text { football] }\end{array}$ & $\begin{array}{l}\text { Don't know what } \\
\text { you're talking } \\
\text { about. } \\
\text { Nothing to do with } \\
\text { me. } \\
\text { Never heard of it. } \\
\text { What do you } \\
\text { mean? }\end{array}$ & $\begin{array}{l}\text { Well, OK if I have to. } \\
\text { l'd rather not get } \\
\text { involved. } \\
\text { I suppose it has to be } \\
\text { done. } \\
\text { I'm not sure if I know } \\
\text { enough. } \\
\text { What if I do something } \\
\text { wrong? }\end{array}$ & $\begin{array}{l}\text { This is important. } \\
\text { We all share this } \\
\text { responsibility. } \\
\text { It's something that must be } \\
\text { done. }\end{array}$ & $\begin{array}{l}\text { We won't get it right first } \\
\text { time. } \\
\text { There is always more to } \\
\text { learn. } \\
\text { We need to keep this under } \\
\text { review. } \\
\text { We need to learn from } \\
\text { others. }\end{array}$ & $\begin{array}{l}\text { Overt/manifest/obvious: } \\
\text { This is complete waste of } \\
\text { time/money. } \\
\text { You'll never stop those } \\
\text { paedophiles. } \\
\text { Abuse just doesn't happen } \\
\text { here. } \\
\text { Covert/latent/hidden: } \\
\text { Yes, of course it matters ... }\end{array}$ \\
\hline $\begin{array}{l}\text { Knowledge and } \\
\text { experience } \\
\text { [What people } \\
\text { know through } \\
\text { experience - } \\
\text { their awareness, } \\
\text { interest or } \\
\text { understanding] }\end{array}$ & $\begin{array}{l}\text { No knowledge } \\
\text { No awareness } \\
\text { No experience } \\
\text { No interest } \\
\text { No motivation }\end{array}$ & $\begin{array}{l}\text { Some limited } \\
\text { knowledge } \\
\text { Some awareness } \\
\text { Some experience } \\
\text { Some interest }\end{array}$ & $\begin{array}{l}\text { Aware of roles and } \\
\text { responsibils } \\
\text { Knowledge appropriate for } \\
\text { role } \\
\text { Knowledge of where to seek } \\
\text { advice and help }\end{array}$ & $\begin{array}{l}\text { Knowledge beyond the } \\
\text { minimum } \\
\text { Experience of handling } \\
\text { referrals/cases } \\
\text { Knowledge of CP systems } \\
\text { outside sport }\end{array}$ & $\begin{array}{l}\text { Overt/manifest/obvious: } \\
\text { Reports known CP failures } \\
\text { Covert/latent/hidden: } \\
\text { Appears knowledgeable but } \\
\text { is actually ignorant of CP }\end{array}$ \\
\hline $\begin{array}{l}\text { Feelings } \\
\text { [What people } \\
\text { feel - their } \\
\text { attitudes and } \\
\text { emotions] }\end{array}$ & $\begin{array}{l}\text { Indifferent } \\
\text { Ignorant } \\
\text { Unwilling } \\
\text { In denial }\end{array}$ & $\begin{array}{l}\text { Fearful, scared } \\
\text { Frightened } \\
\text { Timid } \\
\text { Nervous } \\
\text { Anxious } \\
\text { Sceptical } \\
\text { Reluctant } \\
\end{array}$ & $\begin{array}{l}\text { Accepting } \\
\text { Tolerant } \\
\text { Compliant } \\
\text { Accommodating } \\
\text { Willing }\end{array}$ & $\begin{array}{l}\text { Confident, sure, certain } \\
\text { Convinced } \\
\text { Committed } \\
\text { Positive } \\
\text { Relaxed } \\
\text { Reflective } \\
\text { Evaluative }\end{array}$ & $\begin{array}{l}\text { Overt/manifest/obvious: } \\
\text { Resistance } \\
\text { Hostile } \\
\text { Covert/latent/hidden: } \\
\text { Dishonest } \\
\text { Contradictory }\end{array}$ \\
\hline $\begin{array}{l}\text { Action } \\
\text { [What people } \\
\text { do/have done - } \\
\text { their } \\
\text { achievements } \\
\text { and behaviour] }\end{array}$ & $\begin{array}{l}\text { None } \\
\text { Resistant } \\
\text { Bystander } \\
\text { behaviour }\end{array}$ & $\begin{array}{l}\text { Responds only after } \\
\text { several 'pushes' } \\
\text { Professes ignorance } \\
\text { Asks to be anonymous }\end{array}$ & $\begin{array}{l}\text { Applies knowledge } \\
\text { Fulfils responsibilities } \\
\text { Seeks learning \& } \\
\text { experiences } \\
\text { Attends courses/workshops } \\
\text { Reads literature } \\
\text { Acts appropriately } \\
\text { Engages actively }\end{array}$ & $\begin{array}{l}\text { Keeps up to date } \\
\text { Seeks feedback } \\
\text { Talks about how to improve } \\
\text { Adapts and responds } \\
\text { Seeks wider info sources } \\
\text { Participates in or volunteers } \\
\text { for CP role }\end{array}$ & $\begin{array}{l}\text { Overt/manifest/obvious: } \\
\text { Actively opposes CP work } \\
\text { Covert/latent/hidden: } \\
\text { Own behaviour } \\
\text { belies/contradicts apparent } \\
\text { commitment to CP }\end{array}$ \\
\hline
\end{tabular}


Table 3a Samples from coaches, managers and teachers' interviews

\section{PROACTIVE VOICES:}

- Let's try and get hold of the problem before it becomes one.

- I think teachers wouldn't be doing the job if it (sic) didn't do safety/child protection.

INACTIVE KNOWLEDGE:

- Q: Do you know about the helpline?

A: I've never heard of it.

A: I have heard about it but I don't know a great deal, no.

- $\mathrm{Q}$ : Is there a specified child protection policy?

A: I presume there is .... yes but I don't know for sure.

REACTIVE KNOWLEDGE:

- Q: What do you understand child protection to involve / concern?

A: Well I'd say I wasn't as clued up on it as I should be.

ACTIVE KNOWLEDGE:

- Q: Have any of you done the 3 hour course?

A: Not the FA one but we've all done child protection as part of our work anyway [social worker].

- In terms of sexual abuse, I don't think it's any more prevalent in football than in any other sport.

PROACTIVE FEELINGS:

- Things should be illegal like there's a bloke here today who's smoking on the side line and shouting 'go on son' with a fag hanging out of his mouth, it shouldn't be happening.

- The Charter Mark [kitemarking scheme] should be in place and that if clubs haven't reached that certain level and they haven't got an understanding of children's needs ...

INACTIVE ACTION:

- Q: How does your club deal with these kinds of things [types of abuse]? A: That's not one for me to answer .... because I have never come across it. REACTIVE ACTION:

- It's just to watch your own back in one sense ... You feel like you shouldn't have to do it [CP] but legally you've got to.

- In a sense we wouldn't deal with them [abusers] until they sort of came up. ACTIVE ACTION:

- We've removed some parents from the sidelines.

PROACTIVE ACTION:

- If we find out they were bullying someone then they would be asked to leave. We don't tolerate that sort of behaviour. They know that. 
Measuring the impact of child protection ...

\section{Table 3b Samples from parents/carers and guardians' interviews}

\section{ACTIVE VOICES:}

- Q: How well are CP policies being implemented in your club?

A: I'm perfectly confident that they are.

A: It's a positive environment

A: I think generally it is very well run, organized.

- Q: How seriously are $\mathrm{CP}$ roles taken at the club?

A: I think very seriously

PROACTIVE VOICES:

- It's got to be fun for the kids. You should let them express themselves, not put them in rigid systems. It shouldn't be win, win, win.

INACTIVE KNOWLEDGE:

- Q: Do you know about the FA helpline?

A: No.

- Q: And did you know about the GOAL campaign?

A: No.

REACTIVE KNOWLEDGE:

- It's just part of it ... common sense like ... if somebody is ill or limping a bit go and sit down

REACTIVE FEELINGS:

- I think it's very sad that our confidence ... in actually being physically loving and intimate with our children is being undermined by, you know, the attitude of the media.

ACTIVE FEELINGS:

- I'd feel quite safe to let my son go if I or anyone from my family couldn't attend.

INACTIVE ACTION:

- This is a very new club and a small club and those roles haven't been delegated yet.

- We're not involved with the way it's run.

REACTIVE ACTION:

- I go over sometimes because I know he likes somebody else to be there in case of false allegations.

- We signed a consent form I think

PROACTIVE ACTION:

- $\mathrm{Q}$ : Is there a specific child protection policy?

A: Yes. We have consent forms, medical details, doctors' details, the whole shebang - nothing is left to chance. 